\title{
AVISO METEOROLÓGICO E GEOINFORMAÇÃO COM ÊNFASE À DEFESA CIVIL ${ }^{1}$
}

\author{
GeOgRAFIA, Rio Claro, v. 43, n. 2, p. 338-350, mai./ago. 2018.
}

\section{INTRODUÇÃO}

Os desastres naturais decorrentes dos fenômenos meteorológicos adversos, em razão dos prejuízos humanos e materiais, podem ser considerados um dos maiores problemas enfrentados pelas sociedades na atualidade. No contexto do gerenciamento de riscos de desastres naturais, os avisos meteorológicos são fundamentais para o planejamento das comunidades, Defesa Civil e para os tomadores de decisão da União.

No geral, as causas e consequências, bem como as respostas e as ações para prevenção e mitigação vêm se tornando temas de grande interesse após inúmeros alertas da comunidade científica sobre o potencial de mudanças ambientais em larga escala, como as alterações climáticas, que resultam em aumento da frequência e intensidade das chuvas e de outros eventos extremos. Conhecer esses riscos, as peculiaridades da região e a gestão de defesa civil, possibilita priorizar a adoção de políticas publicas e modelos eficazes voltadas para a prevenção, minimizando os impactos dos desastres naturais sobre a população. E preciso que haja uma vinculação entre as orientações das políticas nacionais, o uso eficaz de sistemas de avisos/alertas e mecanismos que possam transformar os princípios da redução de desastres naturais em atividades locais permanentes, concretas e flexíveis. Neste sentido, pretende-se apresentar um modelo de aviso meteorológico para contribuir com o Sistema Nacional de Proteção e Defesa Civil do Brasil.

Castro (1999) define desastre como:

[...] resultado de eventos adversos, naturais ou provocados pelo homem, sobre um ecossistema vulnerável, causando danos humanos, materiais e ambientais e consequentes prejuízos econômicos e sociais. (CASTRO, 1999, p. 4).

Os desastres provocam uma interrupção grave do funcionamento normal de uma comunidade ou sistema e sua ocorrência está diretamente ligada às condições de riscos existentes em uma localidade e têm efeitos diferentes, porque cada região afetada apresenta condições sociais, econômicas, políticas, geográficas e sanitárias particulares.

No Brasil, os principais fenômenos relacionados a desastres naturais são derivados da dinâmica externa da Terra, tais como, inundações e enchentes, escorregamentos de solo e tempestades. É durante os períodos chuvosos que mais sofremos a ação dos desastres naturais, devido estarem diretamente relacionados a eventos pluviométricos intensos e prolongados; exclusivamente, nos períodos chuvosos que correspondem ao verão, período em que são registrados os maiores índices pluviométricos nas regiões Sul e Sudeste; e, ao inverno na região nordeste (TOMINAGA et. al., 2009).

\footnotetext{
${ }^{1}$ Trabalho apresentado ao Departamento de Operações do Centro Nacional de Pesquisas e Estudos Climáticos (CPTEC), vinculado ao Instituto Nacional de Pesquisas Espaciais (INPE)/MCTI, em maio de 2016. Rodovia Dutra, Km 39, Cachoeira Paulista -SP.
} 
O ano de 2010 no Brasil foi marcado pelos desastres naturais, onde, o estado do Rio de Janeiro apresentou graves cenários, destacando-se as ocorrências de desastres em Angra dos Reis, vitimando 53 pessoas e, as chuvas do mês de abril que provocaram deslizamentos em diversos municípios do Estado, resultando em mais de 200 óbitos. Em 2011, ainda no Rio de Janeiro, ocorreram diversos deslizamentos nos municípios de Nova Friburgo, Teresópolis, Petrópolis, Sumidouro e São José do Vale, com 912 óbitos (ALMEIDA et. al., 2012). Os desastres naturais de grandes proporções, também foram registrados em outros estados como: Pernambuco, Alagoas, Bahia, Espírito Santo, Minas Gerais, São Paulo, Santa Catarina, Acre e Amazonas.

O aumento da incidência dos desastres naturais é explicado paralelamente ao intenso processo de urbanização, com alta densidade populacional e crescimento desordenado das cidades, que o Brasil tem apresentado. A expansão das cidades em direção às áreas impróprias e que apresentam riscos para a ocupação é impulsionado pela especulação imobiliária e pela desigualdade social, explicando assim a formação de favelas, áreas sem qualquer tipo de infraestrutura, de condições básicas e de segurança para se viver, aumentando a vulnerabilidade e os riscos da sociedade (LOPES et. al., 2011).

Neste sentido, os desastres naturais tanto inundações como os deslizamentos de encostas têm aumentado consideravelmente nas últimas décadas, principalmente nos centros urbanos e são agravados em função da urbanização intensa e da construção de habitações em áreas de risco com declividade acentuada, várzeas, próximas aos corpos hídricos, alterando a paisagem urbana.

Atualmente, com a tecnologia existente, criou-se sistemas de monitoramento e alerta (não obstante os avisos) destes eventos, para atuar em diversas frentes, agindo de forma preventiva na ocorrência dos desastres naturais. Porém, como consequência, os sistemas em operação, utilizando um conjunto de dados meteorológicos em tempo real, dados observacionais provenientes de satélites, radares e Plataformas de Coleta de Dados (PCD), e modelos de previsão; usualmente têm trabalhado de forma a monitorar as condições hidrometerológicas emitindo avisos/alertas às comunidades a serem atingidas.

Cada sistema de aviso/alerta com suas particularidades englobam as etapas de monitoramento constante das áreas de risco, previsão de eventos e decisão; que buscam permitir que as autoridades competentes tomem decisões de prevenção, divulgação e coordenação de trabalhos junto à população residente em áreas atingidas.

Argumenta-se que os eventos naturais, e suas consequências, estão inseridos no contexto espacial de análise, no campo de Gerenciamento de Desastres Naturais (GDN), onde, nos Processos de Tomada de Decisão (PTD) encontra-se uma problemática estrutural, que envolvem muitas informações, objetivos conflitantes, com muitas variáveis e parâmetros de análise, com carência de alternativas de soluções ótimas e busca por soluções satisfatórias a nível nacional. Neste contexto, é de suma importância que o aviso meteorológico seja envaido com boa antecedência.

Hoje, a maioria das Defesas Civis no mundo se organiza em sistemas abertos com a participação dos governos locais e da população no desencadeamento das ações preventivas e de resposta aos desastres seguindo o princípio da Defesa Comunitária (CEPED-UFSC, 2012, p. 27). Para Tenan (1974),

A Defesa Comunitária está fundamentada no principio de que nenhum governo tem capacidade para solucionar todos os problemas que possam afetar a comunidade. Sendo assim, torna-se imprescindível que o povo coopere com as autoridades governamentais para que, no seu próprio interesse, sejam resolvidos os diferentes problemas que possam afetar a comunidade (TENAN, 1974, p. 32).

A Defesa Civil no Brasil está organizada sob a forma de sistema e com a aprovação da Lei no 12.608, de 11 de abril de 2012, a sistematização da gestão do risco e dos desastres naturais passa a ser denominada como Sistema Nacional de Proteção e Defe- 
sa Civil (SINPDEC) centralizado pela Secretaria Nacional de Defesa Civil, órgão do Ministério da Integração Nacional.

A Política Nacional de Proteção e Defesa Civil (PNPDEC), lançado em agosto de 2012, ocasião da reinauguração do CENAD e por meio da Lei no $12.608 / 2012$, reflete as ações de prevenção, mitigação, preparação, resposta e recuperação. As ações perfazem - ciclo da gestão de riscos e gerenciamento de desastres (Figura 1). Porém, essas ações não devem ser entendidas de modo exclusivamente linear.

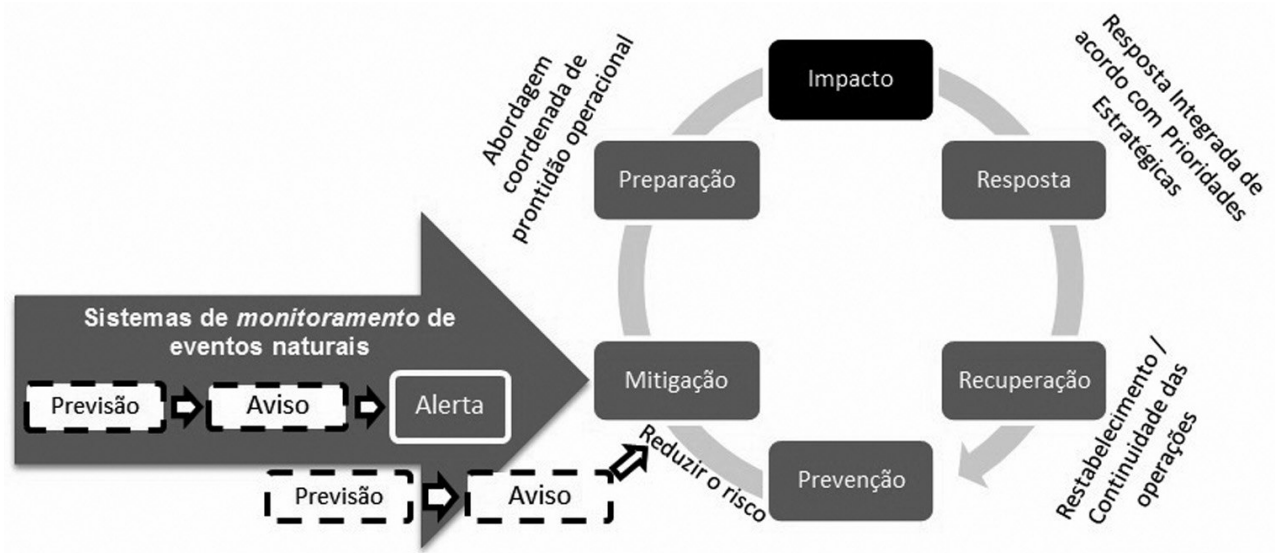

Figura 1 - Ciclo da gestão de riscos e gerenciamento de desastres

Elaboração: Almeida.

Uma ação de mitigação essencial à gestão de riscos de desastre é a estruturação de "sistemas de monitoramento de eventos naturais". Essa ação objetiva identificar avanço de ameaças naturais, apontando se elas representam, ou não, algum risco potencial para desastre. Ademais, as ameaças naturais tem caráter complexo e dinâmico, devendo, portanto serem previstos (quando possível) e monitorados para emissão de avisos, que por sua vez também oferecem suporte para alertas (Figura 1).

A figura 1 também representa que o aviso é uma ação que antecede um alerta. Portanto, com o aviso, pode-se ter um maior tempo hábil para a tomada de decisões, em relação a um alerta, onde este último é muitas vezes emitido na iminência de um desastre. Mas o alerta é necessário por ratificar as áreas dos avisos que oferecem um maior risco potencial para sofrer um evento natural adverso.

Com o propósito de apresentar resultados mais eficientes na gestão de risco e de desastres no Brasil, a Lei no $12.608 / 2012$ passou a interagir com diversas políticas setoriais, principalmente com as políticas relacionadas ao ordenamento territorial, desenvolvimento urbano, saúde, meio ambiente, mudanças climáticas, gestão de recursos hídricos, geologia, infraestrutura, educação, ciência e tecnologia (CEPED-UFSC, 2012, p. 31). Neste contexto, a estrutura organizacional de Defesa Civil foi concebida na forma de sistema, o que lhe confere caráter multidisciplinar dos órgãos setoriais nos três níveis de governo.

A finalidade do Sistema Nacional de Proteção e Defesa Civil - SINPDEC é atuar no processo de planejamento, articulação, coordenação e execução de programas, projetos e ações de proteção e defesa civil.

Neste contexto, destaca-se a criação do Centro Nacional de Monitoramento e Alertas de Desastres Naturais (CEMADEN/MCTI), em funcionamento 24 horas por dia, 
desde o final de 2011, com a missão de monitorar o território brasileiro e emitir alertas de desastres naturais para melhor subsidiar as ações de preparação e resposta do Sistema Nacional de Defesa Civil (SINDEC). Já o Centro Nacional de Gerenciamento de Riscos e Desastres (CENAD/MI), foi criado pelo Decreto no 5.376 , de 17 de fevereiro de 2005, pertence ao Ministério da Integração Nacional e é coordenado pela Secretaria Nacional de Defesa Civil. Na ocasião do lançamento do Plano Nacional de Gestão de Riscos e Respostas a Desastres, O CENAD foi reinaugurado em agosto de 2012, com funcionamento 24 horas por dia, inclusive finais de semana e feriados; tendo, como objetivo gerenciar, com agilidade, ações estratégicas de preparação e resposta a desastres em território nacional e, eventualmente, também no âmbito internacional. Cabe ao CENAD consolidar as informações sobre riscos de desastres no país, possibilitando ao Centro apoiar estados e municípios nas ações preparação e resposta para desastres junto às comunidades mais vulneráveis; sendo que o aviso/alerta ocorre de acordo com a intensidade do evento adverso.

Dada a importância de suas ações e a complexidades de sua gestão, o CENAD atua em parceria com outros órgãos, como: o Centro Nacional de Monitoramento e Alertas de Desastres Naturais (CEMADEN), o Serviço Geológico do Brasil (CPRM), o Instituto Brasileiro do Meio Ambiente e dos Recursos Naturais Renováveis (Ibama), a Agência Nacional de Águas (ANA), a Agência Brasileira de Inteligência (Abin), o Centro de Previsão de Tempo e Estudos Climáticos (CPTEC/INPE), o Instituto Nacional de Meteorologia (Inmet) e o Centro Gestor e Operacional do Sistema de Proteção da Amazônia (Censipam), dentre outros. Segundo Shadeck et. al, (2013, p. 21):

\begin{abstract}
Outras parcerias de fundamental importância são aquelas estabelecidas entre o CENAD e órgãos de meteorologia, tanto aqueles atuantes em nível nacional quanto nos Estados. Diversas parcerias que possibilitam o acompanhamento de informações com órgão de previsão e monitoramento meteorológico foram realizadas, cabendo ressaltar, do ponto de vista nacional: a obtenção de dados em tempo real, previsões meteorológicas e climáticas (esta realizada em consenso com CPTEC e demais órgãos) do INMET (Instituto Nacional de Meteorologia); e pesquisas, previsões meteorológicas e monitoramento realizado pelo CPTEC/INPE (Centro de Previsão do Tempo e Estudos Climáticos). Reforçando a importância de uma atuação mais local, a obtenção de avisos e previsões meteorológicas de diversos órgãos de atuação regional, constitui atividade rotineira no trabalho realizado pelos especialistas. (SHADECK et. al., 2013, p. 21).
\end{abstract}

Neste contexto, o presente trabalho teve como objetivo desenvolver um modelo de aviso meteorológico com o intuito de melhor atender as necessidades do Sistema Nacional de Proteção e Defesa Civil (SINPEDEC), em termos de rapidez e confiabilidade de execução.

\title{
PROCEDIMENTOS METODOLÓGICOS
}

A vantagem proporcionada pelo modelo deve-se ao fato de o meteorologista, através de uma aplicação computacional amigável, possa emitir o aviso meteorológico com facilidade e rapidez. Foi implementado no modelo a rotina de emissão de avisos pelo método de informação geográfica (geoinformação), por meio de linguagens PHP e Javascript, conjuntamente com Google Maps Javascrit API.

A seguir, são apresentados os aspectos conceituais de Sistemas de Informação Geográfica (SIG), Classificação e Codificação Brasileira de Desastres Naturais (COBRADE) e partes da tela de interface da aplicação computacional apresentada para o usuário emitir um aviso meteorológico. 
Geoinformação e emissão de Aviso Meteorológico - Aspectos conceituais e de implementação.

Ressalta-se que geoprocessamento representa qualquer tipo de processamento de dados georreferenciados realizado através do uso de Sistemas de Informação Geográfica (SIG), que envolve diversos componentes como pessoas, dados, software, hardware e metodologias (Figura 2).

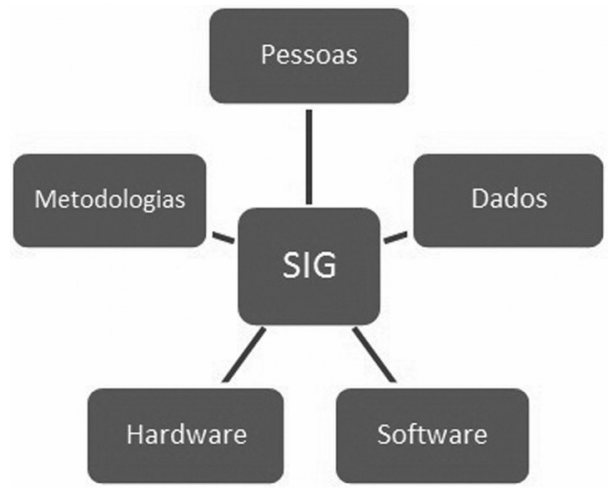

Figura 2 - Elementos de um SIG

Elaboração: Almeida.

Nesse sentido, com os dados obtidos pelas metodologias de previsão de tempo e monitoramento, os meteorologistas poderão utilizar uma aplicação computacional para emissão de um Aviso Meteorológico reportando as áreas com risco de ocorrência de fenômenos meteorológicos adversos e maior potencial para um desastre.

De posse dos dados provenientes da previsão de tempo e monitoramento, para a emissão de um Aviso Meteorológico nos moldes de geoiformação, inicialmente o meteorologista deverá plotar no mapa o polígono da região com potencial para ocorrência de fenômeno meteorológico adverso, indicando o período mais favorável para a sua ocorrência.

Para definir as cores das áreas dos avisos (polígonos da região com potencial para ocorrência de fenômeno meteorológico adverso), pode-se adotar uma cor conforme a probabilidade de ocorrência de tempo severo e o risco potencial para um desastre, como representado na matriz simples de risco na figura 3 .

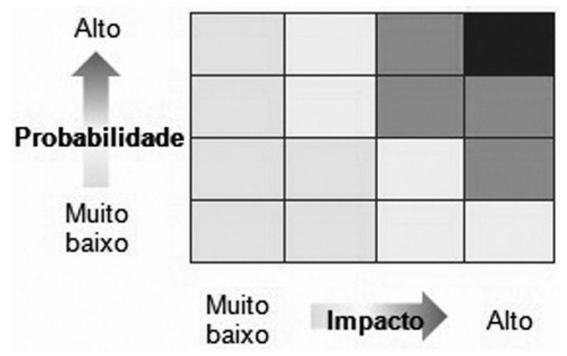

Figura 3 - Matriz de risco

Elaboração: Almeida. 
Uma segunda alternativa para definir as cores das áreas dos avisos é de acordo com a confiabilidade dos modelos meteorológicos utilizados e a severidade do evento meteorológico previsto. Ou seja, conforme as previsões de tempo mais recente que indiquem condições de tempo severo para as próximas horas.

E para a rápida identificação do fenômeno meteorológico previsto, recomenda-se utilizar os ícones (simbologias) do capítulo de desastres naturais do grupo Meteorológico e Climático da Classificação e Codificação Brasileira de Desastres (COBRADE), figura 4.

Passaremos agora a apresentar um roteiro prático para a emissão de um aviso por meio de uma aplicação computacional. Conhecendo a previsão de fenômeno meteorológico adverso, deve-se:

- Plotar no mapa os polígonos (na cor correspondente ao nível da severidade) das áreas com aviso de tempo severo;

- Atribuir o ícone do COBRADE correspondente a previsão de tempo Severo;

- Citar a vigência do aviso;

- Enviar os avisos para o mailing de contatos via e-mail.

A aplicação computacional deverá citar o número do aviso e a data de emissão automaticamente. Devem-se enviar também as eventuais alterações dos avisos, bem como comunicar o sessar dos avisos após a melhora das condições de tempo. O aviso meteorológico reportando previsão de tempo severo, a ser enviado pelo e-mail, necessita ser de fácil e rápido entendimento, com linguagem clara e objetiva. 


\begin{tabular}{|c|c|c|c|c|c|c|c|}
\hline & GRUPO & SUBGRUPO & TIPO & SUBTIPO & DEFINIÇĀOO & COBRADE & SIMBOLOGIA \\
\hline \multirow{9}{*}{ 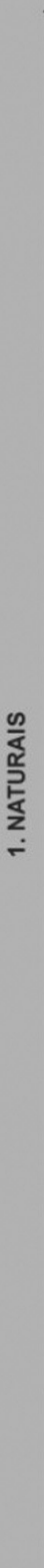 } & \multirow{9}{*}{$\begin{array}{l}\frac{8}{6} \\
\frac{0}{0} \\
\frac{0}{0} \\
\frac{\Phi}{2}\end{array}$} & \multirow[t]{3}{*}{\begin{tabular}{|l|} 
1. Sistemas \\
de grande \\
escala/Escala \\
regional
\end{tabular}} & \multirow[t]{2}{*}{ 1. Ciclones } & $\begin{array}{l}\text { 1. Ventos } \\
\text { costeiros } \\
\text { (mobilidade } \\
\text { de dunas) }\end{array}$ & $\begin{array}{l}\text { Intensificaçäo dos ventos nas regiōes } \\
\text { litorâneas, movimentando dunas de areia } \\
\text { sobre construçőes na orla. }\end{array}$ & 1.3.1.1.1 & \\
\hline & & & & $\begin{array}{l}\text { 2. Marés de } \\
\text { tempestade } \\
\text { (ressaca) }\end{array}$ & $\begin{array}{l}\text { São ondas violentas que geram uma maior } \\
\text { agitação do mar próximo à praia. Ocorrem } \\
\text { quando rajadas fortes de vento fazem subir } \\
\text { o nivel do oceano em mar aberto e essa } \\
\text { intensificaçäo das correntes maritimas } \\
\text { carrega uma enorme quantidade de água } \\
\text { em direção ao litoral. Em consequência, as } \\
\text { praias inundam, as ondas se tornam maiores } \\
\text { e a orla pode ser devastada alagando ruas e } \\
\text { destruindo edificaçōes. }\end{array}$ & 1.3.1.1.2 & \\
\hline & & & $\begin{array}{l}\text { 2. Frentes } \\
\text { frias/Zonas de } \\
\text { convergência }\end{array}$ & 0 & $\begin{array}{l}\text { Frente fria é uma massa de ar frio que avança } \\
\text { sobre uma regiäo, provocando queda brusca } \\
\text { da temperatura local, com periodo de duração } \\
\text { inferior à friagem. } \\
\text { Zona de convergência è uma regiäo que está } \\
\text { ligada à tempestade causada por uma zona de } \\
\text { baixa pressão atmosférica, provocando forte } \\
\text { deslocamento de massas de ar, vendavais, } \\
\text { chuvas intensas e até queda de granizo. }\end{array}$ & 1.3 .1 .2 .0 & \\
\hline & & \multirow[t]{5}{*}{$\begin{array}{l}2 \\
\text { Tempestades }\end{array}$} & \multirow[t]{5}{*}{$\begin{array}{l}\text { 1. Tempestade } \\
\text { local/Convectiva }\end{array}$} & 1. Tornados & $\begin{array}{l}\text { Coluna de ar que gira de forma violenta e } \\
\text { muito perigosa, estando em contato com } \\
\text { a terra e a base de uma nuvem de grande } \\
\text { desenvolvimento vertical. Essa coluna de ar } \\
\text { pode percorrer vários quilômetros e deixa um } \\
\text { rastro de destruição pelo caminho percorrido. }\end{array}$ & 1.3.2.1.1 & \\
\hline & & & & $\begin{array}{l}2 . \\
\text { Tempestade } \\
\text { de raios }\end{array}$ & $\begin{array}{l}\text { Tempestade com intensa atividade elétrica } \\
\text { no interior das nuvens, com grande } \\
\text { desenvolvimento vertical. }\end{array}$ & 1.3.2.1.2 & \\
\hline & & & & 3. Granizo & Precipitação de pedaços irregulares de gelo. & 1.3 .2 .1 .3 & \\
\hline & & & & $\begin{array}{l}\text { 4. Chuvas } \\
\text { intensas }\end{array}$ & $\begin{array}{l}\text { São chuvas que ocorrem com acumulados } \\
\text { significativos, causando múltiplos desastres } \\
\text { (ex.: inundaçöes, movimentos de massa, } \\
\text { enxurradas, etc.). }\end{array}$ & 1.3 .2 .1 .4 & \\
\hline & & & & 5. Vendaval & $\begin{array}{l}\text { Forte deslocamento de uma massa de ar em uma } \\
\text { regiâo. }\end{array}$ & 1.3.2.1.5 & \\
\hline & & $\begin{array}{l}3 . \\
\text { Temperaturas } \\
\text { extremas }\end{array}$ & 1. Onda de calor & 0 & $\begin{array}{l}\text { É um periodo prolongado de tempo } \\
\text { excessivamente quente e desconfortável, onde } \\
\text { as temperaturas ficam acima de um valor normal } \\
\text { esperado para aquela região em determinado } \\
\text { periodo do ano. Geralmente é adotado um } \\
\text { periodo mínimo de três dias com temperaturas } \\
5^{\circ} \mathrm{C} \text { acima dos valores máximos médios. }\end{array}$ & 1.3 .3 .1 .0 & \\
\hline
\end{tabular}

Figura 4 - Classificação e Codificação Brasileira de Desastres (Cobrade) Fonte: CENAD. 
(continuação)

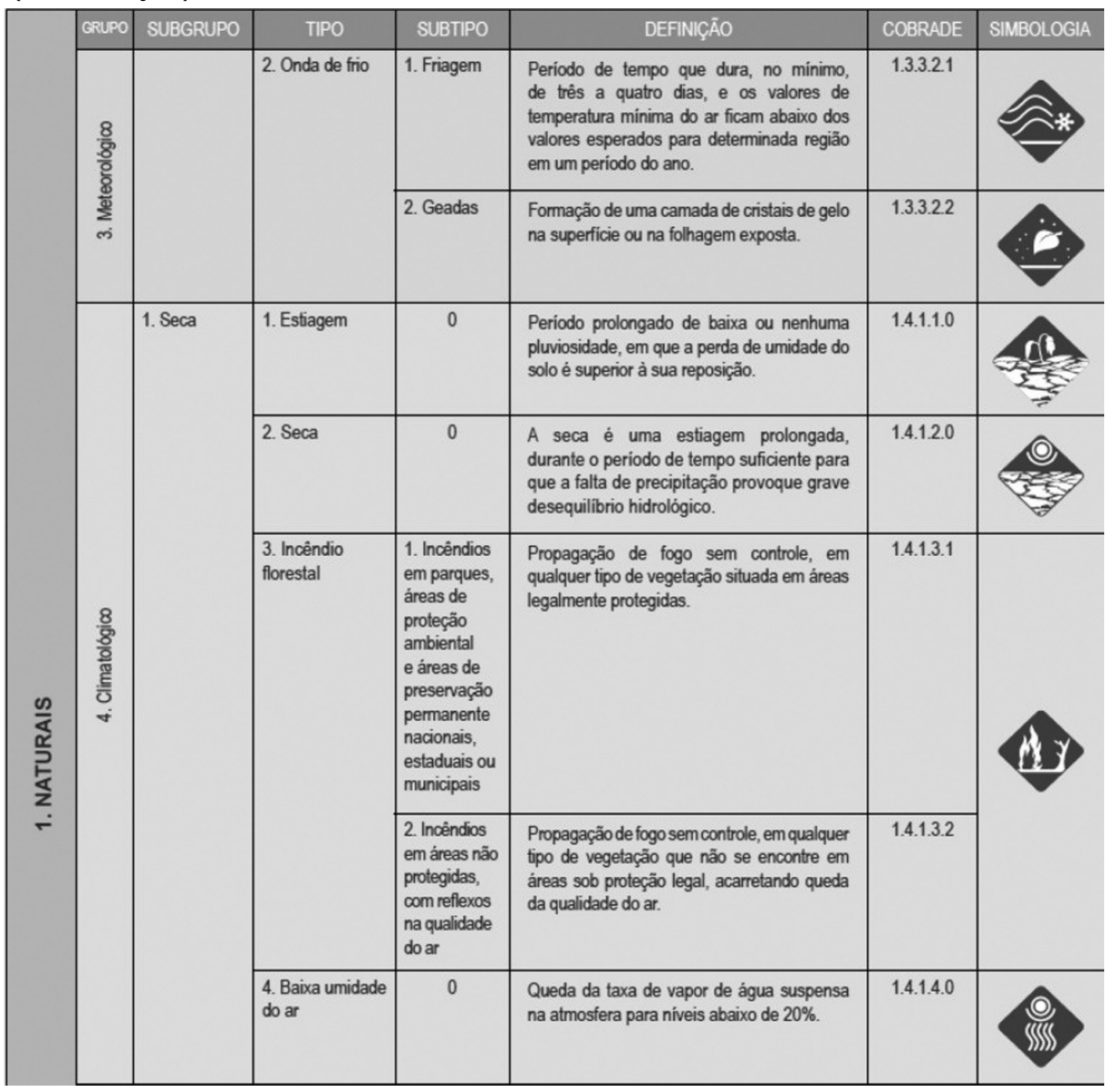

Figura 4 - Classificação e Codificação Brasileira de Desastres (Cobrade)

Fonte: CENAD. 
5):

Abaixo segue a ilustração do corpo de um aviso a ser enviado por e-mail (Figura

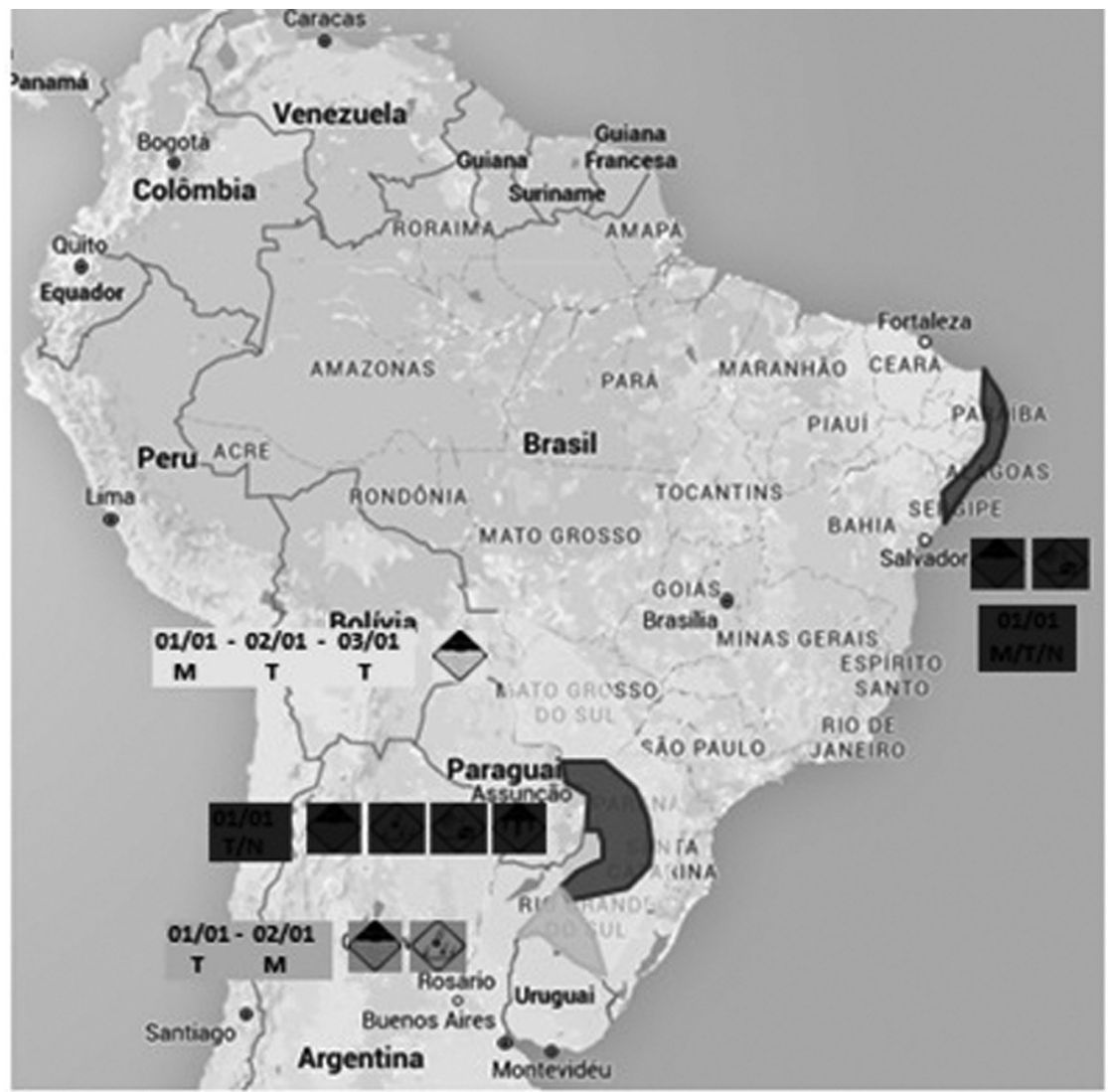

\section{Não há Aviso para Severidade}

Aviso de Observaçäo- decorrer de $120 \mathrm{~h}$

Aviso de Atenção - decorrer de 72h

Aviso Especial - dentro de 24h

Acumulado significativo de chuva; Granizo; 2 Vendava; 17 Tempestade de raios.

Figura 5 - Modelo de aviso meteorológico por meio de geoinformação

Fonte de dados: CENAD (Simbologia); GOOGLE, INEG, ORION-ME (Mapa).

Elaboração: Almeida. 
Para publicação na internet, os avisos de risco de fenômeno meteorológico adverso podem ser mais robustos de informações, além de também explorar a geoinformação. A seguir, exemplos de exibição de avisos meteorológicos em página web (Figuras 6a e 6b).

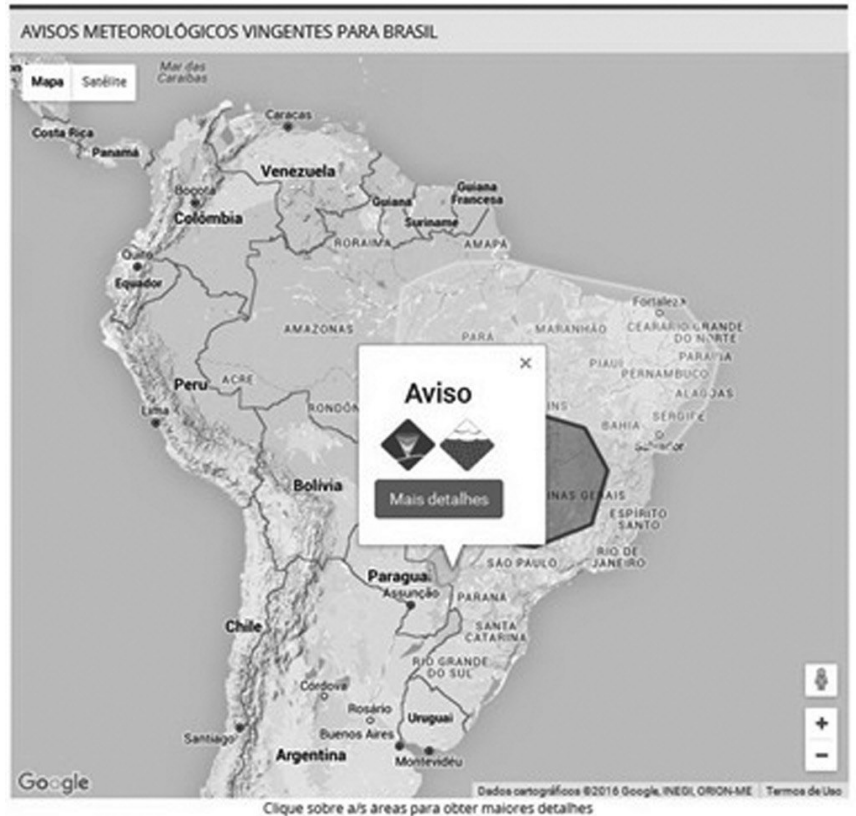

Aviso Excraoedinário de Risco lminento - O tempo extremo if esperads a qualquer momento. Voct deve agir agora para marter-se segue dos posshwis impactos do tempo severo. Niso se descaham danos, irternupples de energa e naco a integridade fisica. Vocé dene evitar as dreas perigosas * siga es consethos dos semipos de emergincia + as recondedes loctir.

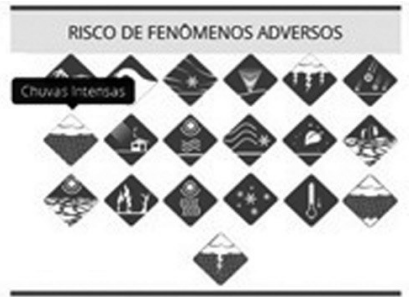

\section{NIVEIS DE AVISOS}

Nabo is previsdo pars severidade - O risco para ocorrencia de fenomeno mesteorologico soverso e pequeno sertero das provimas 163 noras.

Avivo de Observasalo - Hs risco consideravel para ccorrencia de fencmeno meteorolsgico asverso dentro das prowimas 120 noras. para sus maise sepuransa. recomendase acompanhar as preveses meseorologicas mais recertes para que voce posia planejar meenor swas sowioses.

Aviso de Atençaso - Ha risco moderade para exorrencis de fentmeno metescologico adverso denero das provimas 72 neras Acompinhe com mas frequencia as anvinatces da previsas do tempo, pois voce podera necersicac mudar seus planos e se proteger dos eventuais impactos decorrentes de tempo severo. Siga as eventuars recomendactes da Defesa CMil e cas demais autoridases sompetentes:

Aviso Especial - As conolices of tempo sao muto fovoraveis para ocorrencia de um fencmeno meseorologico alverso dentro das prodimas 24 hocas continue atecto score as atualizacoes da previsao do tempo ja que o risco ano para ocorrencia de cemso severo que possam provocar danos e aciserces. Siga as reccmendacies dadefesa CMVll e demais autoridades compesentes, e esteja preparado para mescas of emerpenci com a maior securana possivet

- Aviso Cessado - Haw um risco de fencmeno metecrelogice adveras nas difinas horas Anumente condrotes de tempo apresertem batio niteco para sendrians

\section{$\nabla_{\text {Acumulado significativo de chuva; }} \Leftrightarrow$ Granizo; $\theta$ Vendava; $_{\text {Tempestade de raios. }}$}

\section{Figura 6 (a) - Modelo de aviso meteorológico para Web}

Fonte de dados: CENAD (Simbologia); GOOGLE, INEG, ORION-ME (Mapa). Elaboração: Almeida.

Conforme apresentado no exemplo acima, Figura 6(a), o usuário poderá ver mais detalhes do aviso, clicando sobre o botão "Mais detalhes". Esta ação permite o acesso a outra página com mais informações sobre o aviso, conforme ilustrado na figura $6(b)$. 


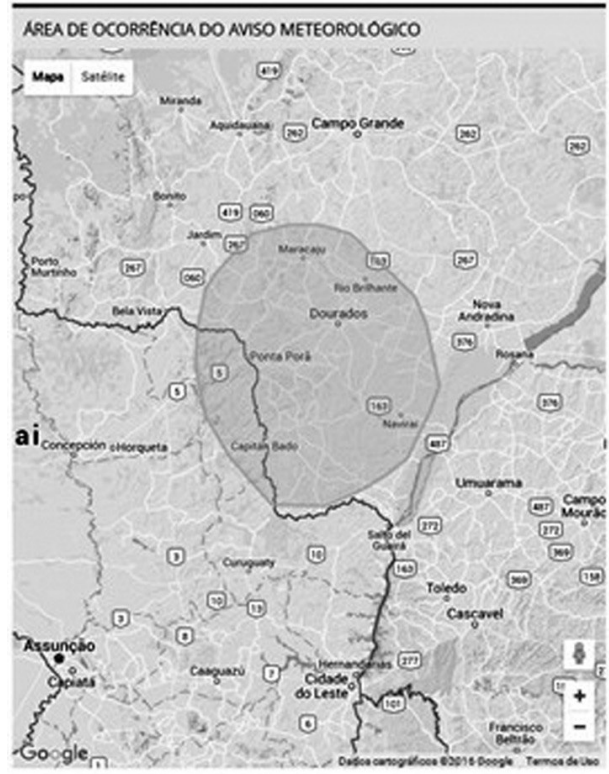

O Aviso Extraordinário de Risco Iminente

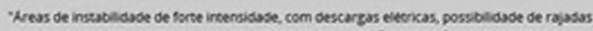

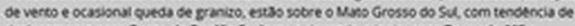
desibcamento para Oeste da Regibo Sudente e devenos atngir areas Dourado-MSe Presidence Prudente-SP em aprowimasamente 24 horas.

\begin{tabular}{|c|c|c|}
\hline Noscoso fesomens soverso & $\begin{array}{l}\text { Ircteodisuse do } \\
\text { Fenomeno. }\end{array}$ & 60 a $80 \mathrm{~mm}$ \\
\hline & vigencix & $24 \mathrm{~h}$ \\
\hline Chuvas Intensas & $\begin{array}{l}\text { Penososcom maver } \\
\text { chance de correnos. }\end{array}$ & $\begin{array}{l}\text { Decorrer do } \\
\text { periodo }\end{array}$ \\
\hline \multirow[t]{2}{*}{ Nisco 00 fenomeno a averss } & $\begin{array}{l}\text { incensisase os } \\
\text { Renomeno. }\end{array}$ & 80 a $120 \mathrm{~km} / \mathrm{h}$ \\
\hline & vetenose & $24 \mathrm{~h}$ \\
\hline Tornado & $\begin{array}{l}\text { Denoso com maice } \\
\text { chance de oxorrenox }\end{array}$ & $\begin{array}{l}\text { Decorrer do } \\
\text { Periodo }\end{array}$ \\
\hline
\end{tabular}

Q Localidades Afetadas

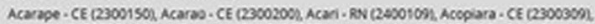

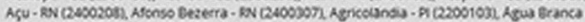

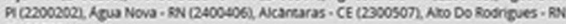
(2400003)

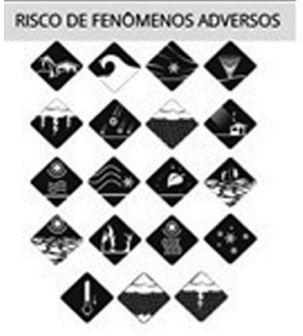

Figura 6 (b) - Modelo de aviso meteorológico para Web

Fonte de dados: CENAD (Simbologia); GOOGLE, INEG, ORION-ME (Mapa). Elaboração: Almeida.

Os exemplos acima permitem disseminar aviso meteorológico com fácil operacionalidade, atendendo de forma eficaz o seu objetivo.

\section{RESULTADOS E DISCUSSÃO}

Para emitir avisos que reportem risco de fenômeno meteorológico adverso, foram utilizadas técnicas de geoinformação e aplicações computacionais, que permitiram enviar os avisos por e-mail e sua publicação na internet.

A aplicação computacional foi desenvolvida nas linguagens PHP e Javascript em arquitetura cliente-servidor, e Google Maps Javascrit API, permitindo ser executado na 
web, para ser operado individualmente pelo meteorologista. O banco de dados usado para armazenamento das tabelas de dados é o MySQL. Para o usuário final, a disponibilização do aviso meteorológico foi por meio de e-mail e/ou de consulta na web.

Este trabalho foi apresentado ao Departamento de Operações do Centro de Pesquisas e Estudos Climáticos (CPTEC), vinculado ao Instituto Nacional de Pesquisas Espaciais (INPE), que por sua vez aprovou e está adotando-o para a reformulação dos seus avisos meteorológicos.

\section{CONSIDERAÇÕES FINAIS}

O uso de geoinformação e aplicações computacionais mostrou ser bastante eficiente para o propósito que foi concebido, principalmente na praticidade da emissão de um aviso meteorológico como no fácil e rápido entendimento do usuário final.

Recomenda-se agora criar ferramentas de validação e índice de acerto dos avisos meteorológicos para auxiliar na busca constante da assertividade dos avisos. Isto também é um objetivo para uma próxima etapa do trabalho.

Finalmente, vale ressaltar a facilidade de emissão de um aviso meteorológico baseado em geoinformação. Basta o meteorologista definir as cores das áreas dos avisos e plotar as áreas de acordo com a confiabilidade dos modelos meteorológicos utilizados e a severidade do evento meteorológico previsto; atribuir o ícone do COBRADE correspondente a previsão de tempo severo; citar a vigência do aviso; enviar os avisos para o mailing de contatos, podendo inclusive publicar na web. A aplicação computacional automaticamente preencherá o número do aviso e a data de emissão.

\section{REFERÊNCIAS}

ALMEIDA et. al., Anuário Brasileiro de Desastres Naturais 2011. Brasília: CENAD, 2012. BRASIL. Câmara dos Deputados. Lei no. 12.608, de 10 de abril de 2012. Institui a Política Nacional de Proteção e Defesa Civil - PNPDEC. Dispõe sobre o Sistema Nacional de Proteção e Defesa Civil - SINPDEC e o Conselho Nacional de Proteção e Defesa Civil CONPDEC. Autoriza a criação de sistema de informações e monitoramento de desastres. Diário Oficial [da] República Federativa do Brasil, Poder Executivo, Brasília, DF, 11 abr. 2012. Seção 1, p. 1.

CASTRO, Antonio Luiz Coimbra de. Manual de planejamento em Defesa Civil. Brasília: Ministério da Integração Nacional, Secretaria de Defesa Civil, 1999.

CEPED - UFSC. Centro Universitário de Pesquisa e Estudos sobre Desastres - Universidade Federal de Santa Catarina. Capacitação básica em Defesa Civil. Florianópolis: CAD UFSC, 2012.

LOPES et. al., Riscos de Escorregamentos: Monitoramento e Alerta de Áreas Urbanas nos Municípios no Entorno de Angra dos Reis - Rio de Janeiro. In: CONGRESSO BRASILEIRO DE GEOLOGIA E DE ENGENHARIA AMBIENTAL, 13. Salvador, 2011. Anais..., Salvador: SIBRADEN, 2011. Disponível em: <http://www.dpi.inpe.br/terrama2/download/papers/ SIBRADEN_2011.pdf>. Acesso em: maio de 2016.

TOMINAGA, L. K.; SANTORO, J.; AMARAL, R. Desastres naturais: conhecer para prevenir. São Paulo: Instituto Geológico, Secretaria do Meio Ambiente, Governo do Estado de São Paulo, 2009.

TENAN, Luiz C. Calamidades brasileiras. Rio de Janeiro: Ministério da Agricultura, Secretaria Geral, 1977. 
SHADECK et. al., Atuação da Secretaria Nacional de Defesa Civil (SEDEC) na Gestão de Riscos e Resposta a Desastres Naturais. In: CONSAD DE GESTÃO PÚBLICA, 6. Brasília, 2013. Anais..., Brasília: CONSAD. Disponível em: <http://consadnacional.org.br/wpcontent/uploads/2013/05/072-A-ATUA\%C3\% 87\%C3\%830-DA-SECRETARIA-NACIONAL-DEDEFESA-CIVIL-SEDEC-NA-GEST\%C3\% 830-DE-RISCOS-E-RESPOSTA-A-DESASTRESNATURAIS.pdf $>$. Acesso em: maio de 2016.

ELTON KLEITON ALBUQUERQUE DE ALMEIDA

(Centro de Previsão de Tempo e Estudos Climáticos (CPTEC), Tecnologista (meteorologista), Rodovia Dutra, Km 39, Cachoeira Paulista -SP. E-mail: eltonkleiton@gmail.com)

\title{
O PENSAMENTO REGIONAL E A ESTRUTURA DA GEOGRAFIA: APRECIAÇÃO HISTORIOGRÁFICA
}

\author{
GEOGRAFIA, Rio Claro, v. 43, n. 2, p. 350-357, mai./ago. 2018.
}

\section{INTRODUÇÃO}

A Geografia tem sido definida como um campo disciplinar abrangente, multidisciplinar e que tem ostentado, ao longo da sua ontologia, evidentes alterações temáticas, e reformulações teóricas, metodológicas e técnicas, não obstante o ramo do saber manter a sua estrutura fundamental e permanente herdada da experiência grecoromana, se é que desejamos valorizar e reconhecer as suas origens mais remotas.

Esta é a representação da Geografia hoje prevalecente, uma representação, portanto, francamente inclusiva, e, inconclusiva. Tal representação revela-se útil seja ao exercício profissional propriamente dito no âmbito da disciplina e aos historiadores mais interessados no nível conceitual/metodológico da construção da Geografia, por um lado, seja aos esforços historiográficos mais culturais ou sociologizados que buscam narrar as experiências da história da disciplina em diferentes contextos temporo-espaciais visando alimentar agendas críticas e análises políticas.

O presente artigo entende que a Geografia, no seu conjunto, exibe uma estrutura articulada conciliando duas possibilidades metodológicas - duas atitudes cognitivas -, nomeadamente, a atitude geral, por um lado, e a atitude corográfica ou regional por outro. Afirma-se aqui que não existe superioridade cognitiva, ou maior precisão científica, ou ascendência ou primazia epistemológica ou de eficácia na produção de "verdades" de um estilo metodológico sobre o outro. Eles são, simplesmente, estilos diferentes nos seus escopos e nos seus respectivos resultados.

$\mathrm{O}$ artigo evidentemente reconhece que os dois estilos cognitivos que a disciplina mostra, o geral e o corográfico, não são eles frutos ou eclosões da experiência têmporoespacial europeia do Iluminismo e da decorrente institucionalização da Geografia. Resulta disto que a crença na fundação moderna da Geografia no formato do pensamento ou da Geografia Regional no ambiente europeu merece ser problematizada. Em primeiro lugar, há de se reconhecer que a noção de fundação carece de qualquer utilidade para a prática profissional no campo da Geografia; em segundo lugar, pode-se franca e seguramente afirmar que a institucionalização da disciplina no final do século 19 é ocasião na qual se formata burocraticamente a metodologia regional - propriamente a domesticação, moderna, digamos assim, do ramo do pensamento geográfico (a corography) cujas origens, cuja fundação mesma remonta às civilizações da Antiguidade. 